1

2 3

4

6

7

8

9

10

11

12

13

14

15

16

17 26 1

\title{
Regenerated chitin fibers reinforced with bacterial cellulose nanocrystals as suture biomaterials
}

Huanling Wu ${ }^{\text {a,b }}$, Gareth R. Williams ${ }^{\text {c }}$, Junzi Wu ${ }^{\text {a }}$, Jianrong Wu ${ }^{\text {a }}$, Shiwei Niu ${ }^{\text {a }}$, Heyu Li $^{\text {a }}$, Haijun Wang ${ }^{\text {, }}$ Limin Zhu ${ }^{\text {a, * }}$

${ }^{a}$ College of Chemistry, Chemical Engineering and Biotechnology, Donghua University, Shanghai 201620, P. R. China

b Jiuzhou College of Pharmacy, Yancheng Vocational Institute of Industry Technology, Yancheng 224005,

P. R. China

c UCL School of Pharmacy, University College London, 29-39 Brunswick Square, London, WC1N 1AX, UK

*Corresponding author:

Prof. Li-Min Zhu, Ph.D,

College of Chemistry, Chemical Engineering and Biotechnology,

Donghua University,

2999 North Renmin Road, Songjiang District,

Shanghai 201620, China,

Tel: +86-21-67792655,

E-mail: $\underline{\text { zhu@dhu.edu.cn }}$

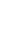

\section{7} 28 9 30 


\section{ABSTRACT}

The objective of this work was to prepare a novel filament with good biocompatibility and mechanical performance which can meet the demands of surgical sutures. Bacterial cellulose nanocrystals (BCNCs) were used to reinforce regenerated chitin (RC) fibers to form $\mathrm{BCNC} / \mathrm{RC}$ filaments. Mechanical performance measurements demonstrated that the strength of the BCNC/RC filament was increased dramatically over the RC analogue. A yarn made of 30 BCNC-loaded fibers also achieved satisfactory mechanical performance, with a knot-pull tensile strength of $9.8 \pm 0.6 \mathrm{~N}$. Enzymatic degradation studies showed the $\mathrm{BCNC} / \mathrm{RC}$ materials to have good biodegradability, the rate of which can be tuned by varying the concentration of BCNCs in the yarn. The RC and the BCNC/RC materials had no cytotoxicity and can promote cell proliferation. In vivo experiments on mice demonstrated that suturing with the $\mathrm{BCNC} / \mathrm{RC}$ yarn can promote wound healing without any adverse effects.

Keywords: Regenerated chitin fiber, Bacterial cellulose nanocrystals, Suture biomaterial, Biocompatibility

\section{7}

(1)

49

50

1

52

3

54
5 


\section{Introduction}

Chitin and bacterial cellulose (BC) are both natural products. Chitin, an abundant and important polysaccharide material in nature, is extracted primarily from shellfish sources such as shrimp and crab. (Jayakumar et al., 2011); it is also found in small amounts in insects and other invertebrate shells. BC is a biopolymer with the same molecular structure as cellulose from plants, but is made from microbial fermentation, but (Amin, Abadi, \& Katas, 2014). Chitin, BC and their derivatives have been widely studied in the field of biomaterials, often due to their excellent biocompatibility (Li et al., 2015; Nguyen et al., 2014; Skołucka-Szary et al., 2015; X. Wang et al., 2016).

Chitin is a biopolymer composed of $\beta-1,4$ glycans of $N$-acetyl- $d$-glucosamine units (Supplementary Information, Fig. S1a). It has low toxicity and biodegradability when implanted in vivo (Anitha et al., 2014; Deepthi, Venkatesan, Kim, Bumgardener, \& Jayakumar, 2016; Pogorielov et al., 2017). Chitosan, also known as deacetylation chitin, is usually obtained by heating chitin with concentrated alkaline solutions, through which the acetyl groups are partially removed. As a result, the water insoluble chitin is converted into soluble chitosan. Because of the wound healing, anti-inflammatory and antibacterial properties of both chitin and chitosan, attempts have been made to use these materials for a range of applications (Ding et al., 2015; Abbas Teimouri \& Azadi, 2016) including wound dressings (Huang et al., 2014; Xie, Khajanchee, Teach, \& Shaffer, 2008), surgical sutures (Dobrovol'skaya, Kasatkin, Yudin, Ivan'kova, \& Elokhovskii, 2015; Khor \& Lim, 2003), and as scaffolds in tissue engineering (Dhivya, Saravanan, Sastry, \& Selvamurugan, 2015; Liu, Ma, Mao, \& Gao, 2011). In particular, chitin and chitosan can promote fibroblast proliferation and macrophage migration, and accelerate vascularization and granulation during wound healing processes (Riccardoaa, 2009). These properties make chitin a promising biomaterial for absorbable scaffolds and sutures. 
However, controlled degradation is essential for a scaffold in tissue engineering applications (Teimouri, Ebrahimi, Emadi, Beni, \& Chermahini, 2015), and is equally important for absorbable sutures. While chitin can be degraded by lysozyme present in the human body, in general it has low biodegradability a major limiting factor for its use in absorbable sutures. As a result, chitosan has attracted more attention in this regard due to its much greater biodegradability. Unfortunately, the mechanical strength of chitosan is very poor, and hence it has mainly been explored for suture coating (Maslova, Uspenskii, Gal'Braikh, \& Kil'Deeva, 2016; Viju \& Thilagavathi, 2013). To improve the quality of chitin such that it can be used for sutures it is necessary to make chemical modifications, or to develop new fiber production (spinning) processes to prepare suturable threads with appropriate properties. A study by Shao et al. (Shao et al., 2015) is an example of the former; these authors prepared a diacetyl chitin suture with good performance.

The latter approach aims to improve the suture properties through adjusting the spinning parameters, especially through the development of novel solvent dissolution and composite formation methods.

Chitin and chitosan can be processed into a range of different forms, for instance membranes and films, pellets or particles, or fibers and filaments. The latter are most commonly prepared using wet spinning (where a polymer is dissolved into a solvent and then extruded into an anti-solvent where it precipitates to form fibers) or dry-jet wet spinning (in which the polymer solution is extruded under heat and pressure into an air gap before entering a coagulation bath). Since the chitin must be dissolved and then reprecipitated, chitin fibers prepared by wet spinning are termed regenerated chitin (RC) fibers.

The majority of studies exploring chitin focus on membranes/films and pellets/particles, with little work concerning spinning. Thus, there is a deficit of knowledge as to the most appropriate parameters to use in producing chitin-based filaments. This is important, because the properties of the spun fiber vary 
significantly with the processing parameters and solvents used. An optimization of the spinning process therefore offers a route to address the many points to be improved during manufacture if chitin or its derivatives are to be used as surgical sutures. For instance, RC materials spun using ionic liquids (Kai, Müller, Beyer, Hermanutz, \& Buchmeiser, 2015; Singh et al., 2016; Singh et al., 2013) have excellent mechanical performance but low biodegradability in vivo. In contrast, RC fibers made using an aqueous acetic acid solution have excellent biodegradability but poor mechanical performance (Yan, Shen, Ji, Yang, \& Shen, 2014). Since the chitin sutures reported to date have limitations in terms of their mechanical strength and/or degradation time, and cannot meet surgical requirements, it is necessary to find a more suitable solvent and to develop a spinning method to produce a fiber with both appropriate mechanical performance and biodegradability.

Cellulose nanocrystals (CNCs) offer a potential route to improving mechanical performance. They have been widely explored for applications such as reinforced composites (Gorgieva, Girandon, \& Kokol, 2017; Ketabchi, Khalid, Ratnam, \& Walvekar, 2016), drug delivery systems (Barbosa et al., 2016; Zainuddin, Ahmad, Kargarzadeh, \& Ramli, 2017), catalysis (An, Long, \& Ni, 2016; Musa, Ahmad, Hussein, Saiman, \& Sani, 2017), optical and electronic materials (Espinha et al., 2016; Gençer, Schütz, \& Thielemans, 2016), enzyme immobilization (Kim et al., 2015; Sunasee, Hemraz, \& Ckless, 2016), and as biosensors (Esmaeili et al., 2015; Schyrr et al., 2014), inter alia. CNCs are short rigid single crystals of cellulose, generally with a width of ca. 5-20 nm and length of 100-300 nm (Habibi, Lucia, \& Rojas, 2010). The chemical structure of cellulose is shown in Fig. S1b (Supplementary Information). The mechanical properties and high length-diameter ratio of $\mathrm{CNCs}$ suggest great potential in the reinforcement of (nano)composites (Lee, Clancy, Kontturi, Bismarck, \& Shaffer, 2016; Leung, Lam, Chong, Hrapovic, \& Luong, 2013). Sources of CNCs include both plant (Chen, Chen, Wang, Yao, \& 
Wang, 2017; Qing et al., 2016; Yang \& Cranston, 2014) and bacterial cellulose (Pirich et al., 2015; Sacui et al., 2014; Vasconcelos et al., 2017; Yoon, 2016). Most CNCs have been obtained from wood pulp or cotton, but there is a problem common to both in that non-cellulose composition such as hemicellulose and ash content present in the raw material must be removed before use. In contrast, BC is very pure, and hence using bacterial CNCs (BCNCs) can obviate the need to remove impurities (Sacui et al., 2014).
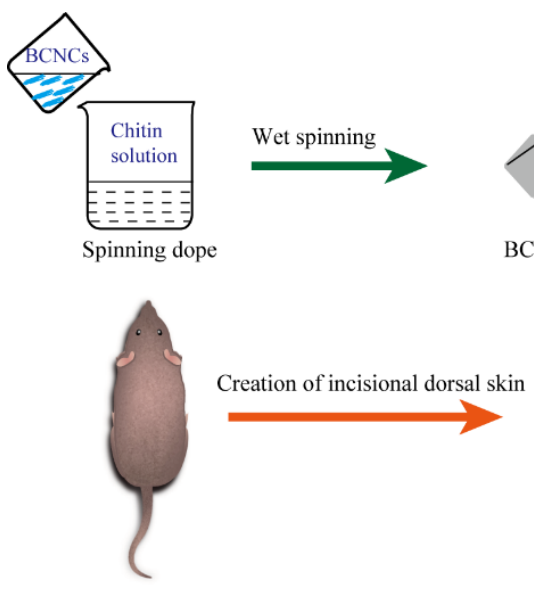

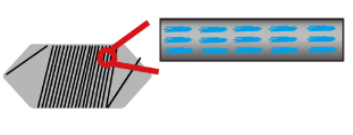

BCNC/RC filaments

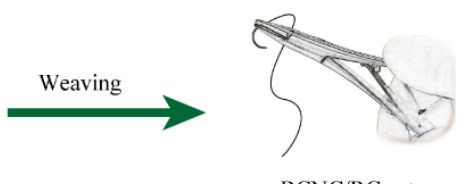

$\mathrm{BCNC} / \mathrm{RC}$ suture
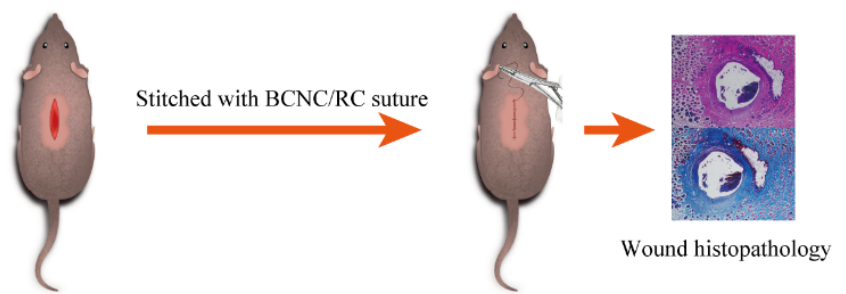

Fig. 1. The process of suture preparation and wound closure.

In this work, we aimed to fabricate a bioresorbable fiber with strong and elastic mechanical performance, and a controllable degradation period. This requires the preparation of a good spinning dope. In preliminary work (data not shown) we found that chitin can be dissolved successfully using a solvent system of $\mathrm{NaOH}$-urea combined with a freeze-thaw process. However, the mechanical properties (e.g. tenacity and strength) of the resultant regenerated chitin (RC) fibers were much worse than those obtained using N,N-dimethylacetamide (DMAc)/lithium chloride ( $\mathrm{LiCl}$ ) as the solvent system. Unfortunately lithium salts have the potential to be toxic to humans, so an alternative approach is required. Here we explored the potential of BCNCs to reinforce chitin-based fibers, preparing BC/chitin blends, processing these into fibers, and then exploring the utility of the latter in wound healing. The 
experimental approach adopted is illustrated schematically in Fig. 1.

\section{Experimental}

\subsection{Materials}

Bacterial cellulose (BC) was provided by the Hainan Yida Co., Ltd. Chitin powder was purchased from Sigma-Aldrich. Lysozyme (biological grade, $\geq 20,000 \mathrm{U} / \mathrm{g}$ ), sulfuric acid $\left(\mathrm{H}_{2} \mathrm{SO}_{4}, 95 \%-98 \%\right.$ ), sodium hydroxide $(\mathrm{NaOH}, \geq 97 \%$ ), and carbamide (urea $\geq 99 \%$ ) were supplied by Sinopharm Chemical Reagents. L929 cells (mouse fibroblast cells) were provided by the Institute of Biochemistry and Cell Biology (Chinese Academy of Sciences). Monofilament polyamide sutures (H501, 3-0, black) were obtained from Shanghai Jinhuan Medical Products Co. Ltd.

\subsection{Preparation and characterisations of bacterial cellulose nanocrystals (BCNCs)}

Preparation of BCNCs. BCNCs were prepared by adapting a literature method (Oliveira et al., 2011; Vasconcelos et al., 2017). Briefly, BC pellets were pretreated using a $0.4 \%$ (w/v) $\mathrm{NaOH}$ solution in water, followed by washing with distilled water until the supernatant reached a neutral $\mathrm{pH}$. Next, the swollen BC pellets were cut into small cubes (ca. 2-5 $\mathrm{mm}^{3}$ ) and processed in an Ultra-Turrax homogenizer (IKA) (no additional water was added). Processing took place at 5,000 rpm for $2 \mathrm{~min}$, and resulted in a cellulosic pulp. The wet pulp was directly hydrolyzed using $\mathrm{H}_{2} \mathrm{SO}_{4}$ (we have found that dried $\mathrm{BC}$ can be easily carbonized by $\left.\mathrm{H}_{2} \mathrm{SO}_{4}\right)$. Cellulosic pulp (5.0 g) was hydrolyzed in aqueous $\mathrm{H}_{2} \mathrm{SO}_{4}$ solutions $(20 \mathrm{~mL})$ of $60 \%$ or $65 \%$ v/v at $35{ }^{\circ} \mathrm{C}$ for $2-3 \mathrm{~h}$, either with stirring (400 rpm) or an ultrasonic treatment (360 W, 40 $\mathrm{kHz}$ ). The cellulose suspension was then diluted with cold ultrapure water to halt the hydrolysis reaction. The resultant white suspension was centrifuged at 11,000 rpm (relative centrifugal force 13,500g) and 4 ${ }^{\circ} \mathrm{C}$ for 10 min to collect the hydrolyzed products, followed by dialysis with regenerated cellulose dialysis 
162

163

tubing (8,000-14,000 MWCO, Thermo Scientific) against ultrapure water until the pH reached a neutral value.

Next, sonication was performed on the BC nanocrystal suspension using a Branson Sonifier (Branson Ultrasonics) for $30 \mathrm{~min}$, within an ice bath. The resulting colloidal suspension was centrifuged at 8,000 $\mathrm{rpm}$ and $4^{\circ} \mathrm{C}$ for $5 \mathrm{~min}$, and the cloudy supernatant collected (see Supplementary Information, Fig. S2a) and stored at $4{ }^{\circ} \mathrm{C}$ prior to use. The BCNC concentration was verified by freeze-drying the supernatant, and found to be approximately $5 \mathrm{mg} / \mathrm{mL}$.

Transmission electron microscopy (TEM). TEM imaging of the hyperfine structure of BC was conducted on a JEM-2100 microscope (JEOL). Samples were diluted to ca. $0.05 \mathrm{mg} / \mathrm{mL}$, then dropcast onto a carbon-Formvar TEM grid. To minimize radiation damage and use the smallest objective aperture for enhancing contrast, measurements were undertaken at an acceleration voltage of $80 \mathrm{kV}$.

Dynamic light scattering (DLS) analysis. The size distribution of the BCNCs hydrolyzed with $65 \%$ $\mathrm{H}_{2} \mathrm{SO}_{4}$ was determined with a laser light scattering (LLS) system (BI-200SM, Brookhaven Instruments) combining static laser scattering and DLS. The BCNCs were sonicated for $10 \mathrm{~min}$ prior to injection into the instrument, and measurements performed in triplicate at $25^{\circ} \mathrm{C}$ and concentrations of $1 \mathrm{mg} / \mathrm{mL}$.

\subsection{Fabrication of fibers and yarns}

Preparation of RC fibers. RC fibers were prepared following a literature method (Huang et al., 2014). $5 \mathrm{~g}$ of chitin powder was dispersed into $100 \mathrm{~g}$ of a solution comprising $\mathrm{NaOH}(11 \% \mathrm{w} / \mathrm{w})$, urea $(4 \%$ w/w), and $\mathrm{H}_{2} \mathrm{O}\left(85 \%\right.$ w/w) with stirring. The resultant suspension was frozen at $-30{ }^{\circ} \mathrm{C}$ for $4 \mathrm{~h}$, and then thawed at room temperature. The freeze-thaw cycle was repeated twice to ensure complete dissolution of the chitin. From this, a transparent chitin solution was obtained (Fig. S2b). A wet-spinning process was next carried out on custom-made apparatus described in our previous work (Wu et al., 2016). A 
nitrogen pressure of $0-0.3 \mathrm{MPa}$ (controlled by a pressure regulator) was used to extrude the chitin solutions $(5 \% \mathrm{w} / \mathrm{w})$ at $1.0 \mathrm{~mL} / \mathrm{min}$ through a commercial spinneret plate containing 30 orifices (diameter: $0.1 \mathrm{~mm})$. The spinning dope was spun into a coagulation bath containing a $10 \%(\mathrm{v} / \mathrm{v})$ aqueous $\mathrm{H}_{2} \mathrm{SO}_{4}$ solution. The resultant RC fibers were rinsed in deionized water for 3 days, with the water changed every $8 \mathrm{~h}$.

Preparation of BCNC/RC fibers. $5.0 \mathrm{~g}$ chitin powder was dispersed into $90 \mathrm{~g}$ of a solution comprising $11 \%(\mathrm{w} / \mathrm{w}) \mathrm{NaOH}, 4 \%(\mathrm{w} / \mathrm{w})$ urea, and $85 \%(\mathrm{w} / \mathrm{w}) \mathrm{H}_{2} \mathrm{O}$ with stirring. The resultant suspension underwent the same freeze-thaw treatment as detailed above to yield a solution. $10 \mathrm{~mL}$ of the BCNC suspension (ca. $5 \mathrm{mg} / \mathrm{mL}$ ) was dispersed into the chitin solution with stirring for $2 \mathrm{~h}$ to prepare the $\mathrm{BCNC} / \mathrm{RC}$ spinning dope. This results in a chitin concentration of $5 \%(\mathrm{w} / \mathrm{w})$, ensuring the $\mathrm{BCNC} / \mathrm{RC}$ fibers can be compared with the RC control. Wet spinning was then performed as described above. Additional spinning dopes were prepared with 5 and $15 \mathrm{~mL}$ of the BCNC suspensions. In each case, the chitin concentration was $5 \% \mathrm{w} / \mathrm{w}$.

Preparation of yarns. The wet-spun fibers underwent twisting and chitin-coating processes in order to provide materials able to match the performance requirements of sutures. A bunch of 30 fibers was twisted using a HC-907 twisting machine (Hengchang Machinery Factory) to yield yarns (Fig. S2c,d). A chitin solution was prepared for coating using the same method as for the RC spinning dope, but with a concentration of $1.5 \% \mathrm{w} / \mathrm{w}$. The twisted yarns were passed through the coating solution at a rate of 0.5 $\mathrm{m} / \mathrm{s}$, before any excess solution on the fibers was removed with a padding mangle, and the yarn passed through a coagulation bath containing a $5 \% \mathrm{v} / \mathrm{v} \mathrm{H}_{2} \mathrm{SO}_{4}$ aqueous solution.

\subsection{Characterization of fibers and yarns}

Morphological analysis. Samples were sputtered with gold to render them conductive, prior to 
observation using a JSM-5600LV scanning electron microscope (SEM; JEOL).

Fourier transform infrared spectroscopy (FTIR). Attenuated total reflectance IR spectra were recorded using a Nicolet-Nexus 6700 FTIR spectrometer (Nicolet Instrument Corp.) over the wavenumber range $500-4000 \mathrm{~cm}^{-1}$ and at a resolution of $4 \mathrm{~cm}^{-1} .32$ scans were recorded per sample.

Mechanical properties. The mechanical properties of single filaments were measured with a T150 UTM Nano tensile test system (Agilent) using a gauge length of $20 \mathrm{~mm}$ and crosshead speed of 20 $\mathrm{mm} / \mathrm{min}$. All samples were preconditioned at $20{ }^{\circ} \mathrm{C}$ and $65 \%$ relative humidity for $24 \mathrm{~h}$ prior to mechanical testing. The stress and strain properties of the BCNC/RC filaments were recorded, and the mean and standard deviation are reported for $n=20$. The knot-pull strength of the BCNC/RC yarn was assessed using a universal testing instrument (AGS-X, Shimadzu) at a speed of $5.0 \mathrm{~mm} / \mathrm{s}$. A commercial polyamide (PA) suture was also explored as a benchmark material. The knot-pull strength was measured ten times using suture materials $20 \mathrm{~cm}$ in length. The samples were incubated in PBS (pH 7.4) for 30 $\min$ at $25^{\circ} \mathrm{C}$ before testing.

Statistical analysis was carried out using the analysis of variance (ANOVA) method, with a post-hoc Tukey test. A value of $\mathrm{p}<0.05$ was considered statistically significant. Data are annotated with $*$ for $\mathrm{p}$ $<0.05, * *$ for $\mathrm{p}<0.01$, and $* * *$ for $\mathrm{p}<0.001$.

\subsection{Enzymatic degradation}

A gravimetric method was applied to estimate the degradation behavior of the $\mathrm{RC}$ and $\mathrm{BCNC} / \mathrm{RC}$ fibers (Kang, Bi, Zhuo, \& Jiang, 2017). The uncoated RC (0.2 g) and BCNC/RC fibers (0.2 g) were placed in $50 \mathrm{~mL}$ of a phosphate buffered solution (PBS; pH 7.4) with lysozyme concentrations of 0.2 $\mathrm{mg} / \mathrm{mL}$ or $1.0 \mathrm{mg} / \mathrm{mL}$. This mixture was then incubated in a shaker at $60 \mathrm{rpm}$ and $37^{\circ} \mathrm{C}$ for different time periods $(1,3,5,7,10$ and 15 days). In order to avoid inactivation of the lysozyme, $10 \mathrm{~mL}$ of the solution 
was removed every day and an equivalent volume of lysozyme solution (in PBS, at 0.2 or $1.0 \mathrm{mg} / \mathrm{mL}$ ) added. At the appropriate time, the fibers were removed from the medium, washed twice with deionised water to remove residual lysozyme, and air-dried until they reached a constant weight. The degradation was quantified in terms of the remaining mass percentage, which was calculated using the following formula:

$$
\text { Remaining mass }(\%)=W_{t} / W_{0} \times 100 \%
$$

Where $W_{0}$ is the initial weight of the fibers and $W_{t}$ the residual weight after incubation with lyzozyme. Results are reported as mean \pm S.D. $(n=3)$.

\subsection{In vitro cytocompatibility}

L929 cells were selected as a model cell line for the cytocompatibility assay, and maintained in Dulbecco's Modified Eagle Medium (DMEM) supplemented with 1\% (v/v) of a pre-made penicillin (100 units $/ \mathrm{mL})$ and streptomycin (100 units/mL) solution, and 10\% (v/v) fetal bovine serum (FBS). $2.0 \mathrm{mg}$ of the $\mathrm{BCNC} / \mathrm{RC}$ filaments and the coated $\mathrm{BCNC} / \mathrm{RC}$ yarns were placed in the wells of 24-well plates, with some wells left empty as a control. The culture plates were sterilized by alcohol steam for $4 \mathrm{~h}$, and PBS then used to wash away any residual alcohol. Next, a suspension of L929 cells (200 $\mu \mathrm{L}$; cell density of $1.0 \times 10^{4}$ cells $\left./ \mathrm{mL}\right)$ was seeded into each well and incubated $\left(37^{\circ} \mathrm{C}, 5 \% \mathrm{CO}_{2}\right)$ for 1 or 3 days.

After incubation, the cells were studied using two different methods. In the first, the culture plates were removed from the incubator, washed with PBS (pH 7.4) twice, and the cell morphology observed under an inverted fluorescence microscope $(200 \times$ magnification, XDS-500D, Zeiss). The second comprised MTT assays. The medium in every well was removed and replaced by $40 \mu \mathrm{L}$ of Thiazolyl Blue Tetrazolium Bromide (MTT) solution $(0.5 \% \mathrm{w} / \mathrm{v})$ and $360 \mu \mathrm{L}$ of fresh DMEM. After incubation at $37{ }^{\circ} \mathrm{C}$ for $4 \mathrm{~h}$, DMSO $(400 \mu \mathrm{L})$ was added to each well and the plates shaken for 30 min at room 
temperature. Afterwards, the solutions in each well were transferred into 96-well plates and the OD values of the resulting purple solutions were measured at $570 \mathrm{~nm}$ with a microplate reader (Multiskan, ThermoFisher). Each experiment contained triplicate conditions, and three independent experiments were performed.

\subsection{Animal experiments}

Animals. Six weeks old male BALB/C mice $(23 \pm 2 \mathrm{~g})$ were supplied by the Shanghai Slack Laboratory Animal Inc. All animal experiments were undertaken following the Guide for the Care and Use of Laboratory Animals published by the US National Institutes of Health (NIH Publication No. 8523, revised 1985) and performed under certificate SYZK 2012-0002 issued by the Shanghai Science and Technology Committee authority, in full accordance with their rules and regulations. Animals were individually housed at $24 \pm 1{ }^{\circ} \mathrm{C}$, at relative humidity of $45-55 \%$ and with $12: 12 \mathrm{~h}$ dark/light cycles. The animals had free access to a standard pellet diet (Shanghai Puluteng Biological Technology Co., Ltd.) and water throughout the experimental protocol, which was based on the Experimental Animal Management Ordinance of the National Science and Technology Committee of the People's Republic of China (1998).

Creation of incisional dorsal skin wounds and suture implantation. Prior to surgery, four animal groups ( $n=6$ per group) were established for the negative control, commercial polyamide (PA) suture, and two of the novel sutures produced in this work as follows:

Group I: Negative control; no sutures.

Group II: Positive control animals sutured with commercial PA product (H501, USP 3-0).

Group III: Animals sutured with twisted and coated BCNC/RC yarn.

Group IV: Animals sutured with twisted but uncoated BCNC/RC sutures. 
All the animals from groups I, II, III and IV were anesthetized with ketamine $(80 \mathrm{mg} / \mathrm{kg})$ and xylazine $(10 \mathrm{mg} / \mathrm{kg})$. Hair on the dorsal region was shaved, and the area cleaned with povidone iodine. A wound was created by making a $20 \mathrm{~mm}$ full-thickness longitudinal incision with a scalpel. The wounded area was then closed by stitching with the different sutures, and the wound covered with cotton gauze. No sutures were applied to the group I (negative control) animals. The mice were resuscitated and monitored daily.

Tissue harvest, processing, sectioning and staining. 5 and 10 days after surgery, 3 mice from each group were sacrificed and hair regrowth removed. The wounds were excised along with an area of normal skin of ca. $5 \mathrm{~mm}$ around the wound, and pinned flat on dental wax prior to fixation. Tissues were fixed in $4 \%$ aqueous paraformaldehyde at $4{ }^{\circ} \mathrm{C}$ for $20 \mathrm{~h}$, prior to processing for paraffin embedding. Sections of the wounds were obtained from horizontal-cutting (illustrated in Fig. S3). The cut paraffin sections (5 $\mu \mathrm{m}$ thickness) were stained with haematoxylin and eosin (HE) and Masson's trichrome for microscopic examination.

\section{Results and discussion}

\subsection{Characterization of $B C N C s$}

Morphology. SEM shows that BC exists as a 3-D fibrous membrane (Fig. 2a). Two different concentrations of $\mathrm{H}_{2} \mathrm{SO}_{4}(60 \%, 65 \%)$ were explored for its acid hydrolysis, and TEM images of the BCNCs obtained after ultrasonic treatment for $30 \mathrm{~min}$ are given in Fig. 2b-d. It can be seen that after being hydrolyzed with $60 \% \mathrm{H}_{2} \mathrm{SO}_{4}, \mathrm{BC}$ partially retains its nanofibril structure, and comprises fibers with widths of 10 s of nanometers and lengths of several micrometers. After treatment with $65 \% \mathrm{H}_{2} \mathrm{SO}_{4}$, BCNCs with width of ca. 20-50 nm and length of 100-300 nm were obtained. A secondary BCNC structure consisting of highly oriented nanofiber bundles with a "bowknot" shape and with diameters 
ranging from a few nanometers to tens of nanometers can be seen in Fig. 2d. The BCNCs clearly have a high length-diameter ratio and a large specific surface area, making them promising as a filling and reinforcing material.
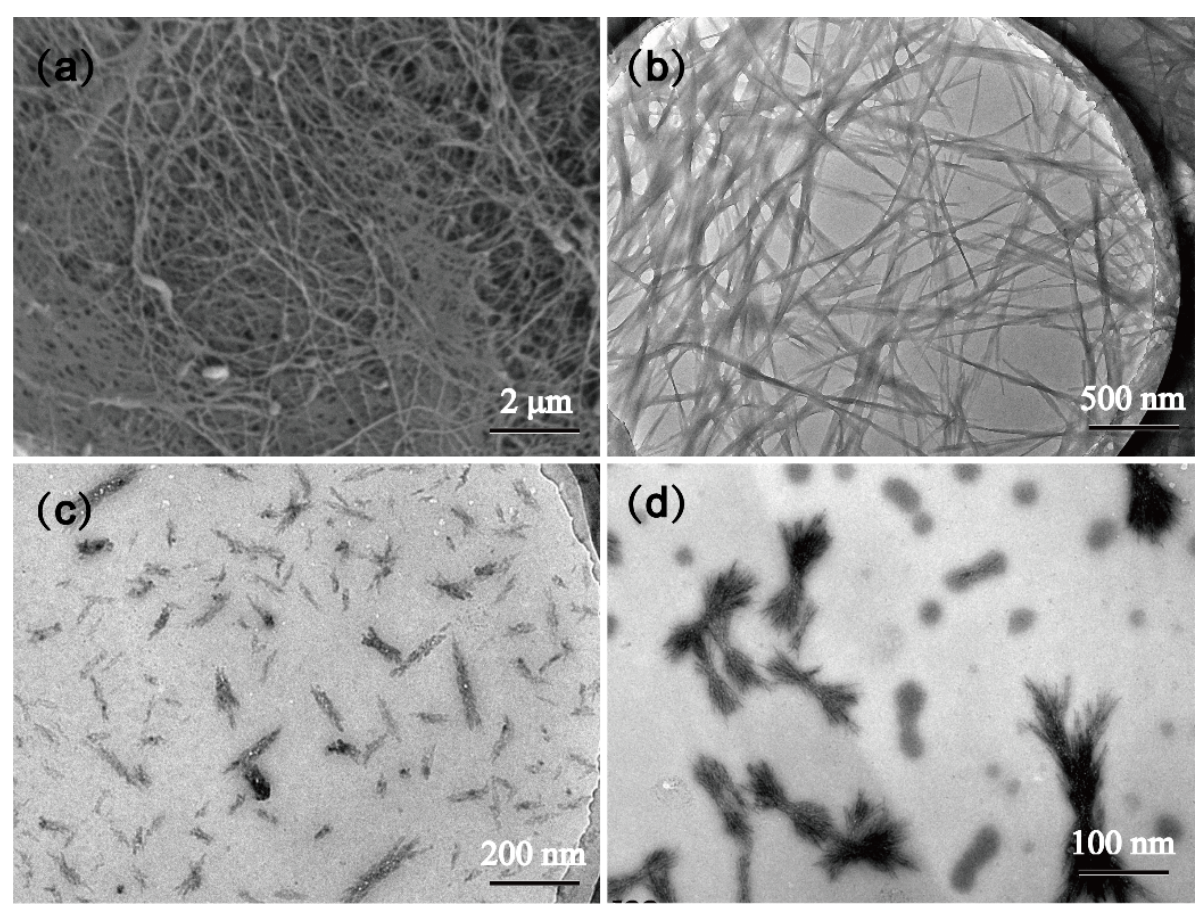

Fig. 2. Electron microscopy data, showing (a) the BC morphology as imaged by SEM, and TEM images of the acid-hydrolysis products of $\mathrm{BC}$ after treatment with (b) $60 \% \mathrm{H}_{2} \mathrm{SO}_{4}$, (c) $65 \% \mathrm{H}_{2} \mathrm{SO}_{4}$ and (d) $65 \%$ $\mathrm{H}_{2} \mathrm{SO}_{4}$ at a higher magnification.

The yield of BCNCs under the different hydrolysis conditions was calculated to be $70.9 \%\left(60 \% \mathrm{H}_{2} \mathrm{SO}_{4}\right)$ and $61.5 \%\left(65 \% \mathrm{H}_{2} \mathrm{SO}_{4}\right)$. Thus, both the yield and the size of the BCNCs can be controlled by adjusting the concentration of $\mathrm{H}_{2} \mathrm{SO}_{4}$ used for reaction. The longer BCNCs from hydrolysis with $60 \% \mathrm{H}_{2} \mathrm{SO}_{4}$ are intertwined with one other, and if these were used to make fibers there is a high probability of these aggregates leading to non-uniformity in the products, for instance in terms of their strength. Hence, although the $\mathrm{BCNCs}$ from treatment with $65 \% \mathrm{H}_{2} \mathrm{SO}_{4}$ were obtained with lower yield, these were adopted for further studies.

$D L S$. In order to investigate the relationship between the size of the nanocrystals and the treatment method, $\mathrm{BC}$ was hydrolyzed with $65 \% \mathrm{H}_{2} \mathrm{SO}_{4}$ either under stirring for $3 \mathrm{~h}$, or with sonication for $2 \mathrm{~h}$ or 
$3 \mathrm{~h}$. The different processing conditions have significant effects on the particle size, resulting in particle sizes of $455.3 \pm 17.6,442.5 \pm 21.6$ and $366.8 \pm 13.2 \mathrm{~nm}$ respectively. The particle size of BCNCs obtained using the ultrasonic method is smaller and more uniform than that of those prepared with stirring, with $2 \mathrm{~h}$ of sonication resulting in particles roughly the same size as $3 \mathrm{~h}$ of stirring. A longer ultrasonication time appears to result in smaller crystals. The crystal size obtained by DLS is larger than that measured by TEM, as expected given the hydrated state of the former, but is consistent with the size of the secondary bundles observed in TEM.

ATR-FTIR. BC and BCNCs treated with $65 \% \mathrm{H}_{2} \mathrm{SO}_{4}$ were characterized by ATR-FTIR (Fig. 3A) to elucidate whether the functional groups of BC have changed after acid hydrolysis. The FTIR spectra of native $\mathrm{BC}$ and the $\mathrm{BCNCs}$ both contain typical cellulose vibration bands. A prominent band is observed around $1100 \mathrm{~cm}^{-1}$ corresponding to asymmetric $\mathrm{C}-\mathrm{O}-\mathrm{C}$ and anhydroglucose ring asymmetric stretching. The band between $3282 \mathrm{~cm}^{-1}$ and $3340 \mathrm{~cm}^{-1}$ reflects stretching vibration of O-H groups, including $\mathrm{CH}_{2}-\mathrm{OH}$ and $-\mathrm{CH}-\mathrm{OH}$. An absorption band at $2900 \mathrm{~cm}^{-1}$ is due to the aliphatic-C-H groups (Chen et al., 2017; Vasconcelos et al., 2017). Overall, Fig. 3A indicates that no chemical changes occurred during acid hydrolysis of $\mathrm{BC}$, with all key cellulosic bands observed to be present. The results are consistent with the expectation that the $\mathrm{BC}$ was not carbonized by $65 \% \mathrm{H}_{2} \mathrm{SO}_{4}$. The band at ca. $1028 \mathrm{~cm}^{-1}$ is noticeably stronger in the $\mathrm{BCNC}$ spectrum than in the pure $\mathrm{BC}$ data, which suggests the presence of some sulfate in the BCNCs. This might indicate that some cellulose sulfate has been generated during the digestion process. 

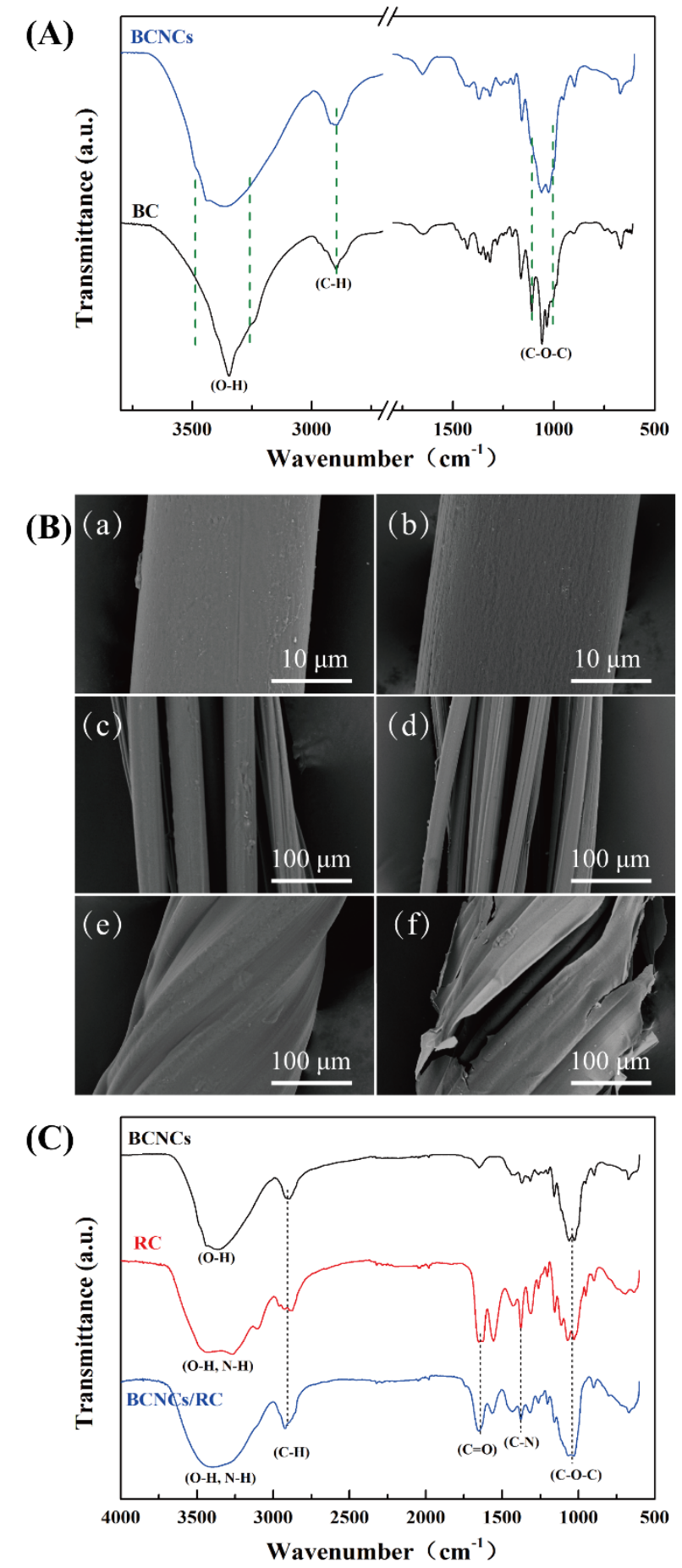

avenumber $\left(\mathrm{cm}^{-1}\right)$

330 Fig. 3. (A) ATR-FTIR spectra of the original BC and BCNCs. (B) SEM images of (a) the RC filament $(5,000 \times)$, (b) the BCNC/RC filament prepared with $10 \mathrm{~mL}$ of BCNC suspension $(5,000 \times)$, (c) the twisted $\mathrm{RC}$ yarn $(500 \times)$, (d) the BCNC/RC yarn made with $10 \mathrm{~mL}$ of BCNCs $(500 \times)$. The yarn made with 10 $\mathrm{mL}$ of BCNCs is shown coated with chitin in (e), and with the coating torn in (f). (C) ATR-FTIR spectra of the BCNCs, RC fiber and BCNC/RC fiber.

\subsection{Fabrication and characterization of $R C$ and $B C N C / R C$ filaments}


to have good compatibility and to mix well. BCNCs could be dispersed very effectively in a chitin solution, with no obvious phase separation observed even if the solutions were left for 10 days. RC and BCNC/RC filaments could easily be fabricated via the wet spinning technology. Fig. 3B(a) and 3B(b) show that both the RC and BCNC/RC filaments have smooth surfaces, and diameters of $19.8 \pm 1.2 \mu \mathrm{m}$ and $20.8 \pm 1.3 \mu \mathrm{m}$ respectively. The surface of the BCNC/RC filament appears rougher, and its diameter is also a little higher than the RC filament. The volume of BCNC suspension added ranged from 5-15 $\mathrm{mL}$, and the suspension has a solid content of ca. $5 \mathrm{mg} / \mathrm{mL}$. Correspondingly, the solid BCNC content of $100 \mathrm{~mL}$ of the spinning dope ranges from $25-75 \mathrm{mg}$. In contrast, the chitin content of the same quantity of spinning dope is $5 \mathrm{~g}$. Therefore, the BCNCs comprise a small proportion of the total solid content of the spinning solution, and thus make little difference to the diameter of the filaments.

The surface morphology of the twisted yarns is depicted in Fig. 3B(c) and 3B(d). The diameter of the yarns is about $200 \mu \mathrm{m}$, and there are no obvious differences between the $\mathrm{RC}$ and $\mathrm{BCNC} / \mathrm{RC}$ materials. Fig. 3B(e) displays the surface appearance of the coated yarn. The fibers are completely enveloped inside the coating. If the coating is deliberately torn, the inner fibers are easily seen (Fig. 3B(f)). A summary of the key parameters of the yarns is given in the Supplementary Information (Table S1).

FTIR. ATR-FTIR spectra of the BCNCs, RC fibers and BCNCs/RC fibers are given in Fig. 3C. The chemical structures of cellulose and chitin are very similar, and thus their IR spectra contain peaks in the same locations. Signals at ca. $3350 \mathrm{~cm}^{-1}$ correspond to $\mathrm{O}-\mathrm{H}$ or $\mathrm{N}-\mathrm{H}$ stretches, the band between 2850 and $3000 \mathrm{~cm}^{-1}$ to asymmetric and symmetric $\mathrm{C}-\mathrm{H}$ stretching, and the peaks present between 1000 and $1150 \mathrm{~cm}^{-1}$ are attributed to asymmetric $\mathrm{C}-\mathrm{O}-\mathrm{C}$ bridge and anhydroglucose ring asymmetric stretching. The main difference between the spectra lies in the presence of absorption peaks at 1652 and $1377 \mathrm{~cm}^{-1}$ for chitin; these correspond to $\mathrm{C}=\mathrm{O}$ and $\mathrm{C}-\mathrm{N}$ bonds, respectively. The spectra of the 
BCNC/RC fibers show no obvious differences from the RC fiber, demonstrating that the BCNCs and chitin are simply physically mixed and no new functional groups are produced. The low weight percentage of the BCNCs in the BCNC/RC fibers mean that their FTIR spectrum is dominated by features from RC.

Mechanical characterization. The effect of the BCNCs on the mechanical properties of RC filaments is summarized in Table 1. When the volume of the BCNC suspension added was increased from 0 to 10 $\mathrm{mL}$, the ultimate stress increased from $126.5 \pm 11.5$ to $186.2 \pm 12.4 \mathrm{MPa}$, while the strain decreased slightly from $9.7 \pm 1.1 \%$ to $8.3 \pm 0.7 \%$. A number of studies have shown that the addition of cellulose nanocrystals (CNCs) can increase the strength of a matrix, but decreases extensibility. Some authors have suggested that it is the aggregation of the CNCs which leads to this reduction (Lee et al., 2016; B. Wang, Torresrendon, Yu, Zhang, \& Walther, 2015), while others propose that the CNCs restrict the motion of the matrix due to strong intermolecular interactions between the two components (Cao, Dong, \& Li, 2007; Saralegi et al., 2013). Thus, the addition of the BCNCs causes agglomeration effects or limits the slippage of the chitin macromolecules (or both); this increases the strength of the fibers, but at the expense of extensibility. However, the latter remains high, fully appropriate for suture applications, and the key aim of increasing mechanical strength has been achieved with $10 \mathrm{~mL}$ of BCNCs. In contrast, both the stress and strain decrease when the volume of BCNC suspension was raised to $15 \mathrm{~mL}$.

A statistical analysis of the mechanical data of the fibers was performed, and the results are shown in Fig. S4 and Fig. S5. It can be seen from Fig. S4 that the ultimate stress of all fibers with BCNCs added is significantly greater than the control fibers with no BCNCs. Similar observations for stress can be made (Fig. S5), with all BCNC-containing fibers having stress significantly lower than the control. There are also differences between the mechanical strength and elasticity of the fibers when the amount of 
381

382

383

BCNCs added increases from $5 \mathrm{~mL}$ to $15 \mathrm{~mL}$. There is a significant increase in strength upon going from 0 to $5 \mathrm{~mL}$ to $10 \mathrm{~mL}$, and then a significant decrease moving from 10 to $15 \mathrm{~mL}$. There is no significant difference between the strength of fibers incorporating $15 \mathrm{~mL}$ and $5 \mathrm{~mL}$ of the BCNC suspension. Considering the elasticity, there is a general decline in strain as the amount of BCNCs added rises, which is significant upon moving from 0 to $5 \mathrm{~mL}$ but not between 5 and $10 \mathrm{~mL}$ or 10 and $15 \mathrm{~mL}$. There is however a significant difference between the $15 \mathrm{~mL}$ and $5 \mathrm{~mL}$ fibers in strain terms. Overall, the results indicate that the addition of $10 \mathrm{~mL}$ of BCNCs appears to mark a transition point in the fiber properties, and it can be concluded that 5-10 $\mathrm{mL}$ of the BCNC suspension should be used to produce fibers with optimum mechanical properties. The flexibility and extensibility of chitin fibers are very high, and therefore the slight decrease in extensibility upon BCNC addition should not compromise the application of the fibers.

\section{Table 1}

Mechanical properties of the RC and BCNC/RC filaments (mean \pm S.D., $\mathrm{n}=20$ ).

\begin{tabular}{cccc}
\hline $\begin{array}{c}\text { Volume of BCNCs } \\
\text { added }(\mathrm{mL})\end{array}$ & Fiber diameter $(\mu \mathrm{m})$ & Ultimate stress $(\mathrm{MPa})$ & Ultimate strain $(\%)$ \\
\hline 0 & $20.5 \pm 1.7$ & $126.5 \pm 11.5$ & $9.7 \pm 1.1$ \\
5 & $21.2 \pm 1.5$ & $157.6 \pm 11.8$ & $8.8 \pm 1.0$ \\
10 & $22.4 \pm 1.6$ & $186.2 \pm 12.4$ & $8.3 \pm 0.7$ \\
15 & $23.5 \pm 1.8$ & $153.3 \pm 13.5$ & $7.8 \pm 0.7$ \\
\hline
\end{tabular}




\section{Table 2}

Knot-pull tensile strength of the $\mathrm{RC}$ and $\mathrm{BCNC} / \mathrm{RC}$ yarns before and after PBS impregnation (mean \pm S.D., $\mathrm{n}=10)$.

\begin{tabular}{|c|c|c|}
\hline \multirow{2}{*}{ Sample } & \multicolumn{2}{|c|}{ Knot-pull tensile strength (N) } \\
\hline & Unimpregnated & Impregnated in PBS for $24 \mathrm{~h}$ \\
\hline $\mathrm{RC}$ yarn & $8.6 \pm 1.1$ & $6.9 \pm 0.5$ \\
\hline $\mathrm{RC}$ yarn with coating & $6.3 \pm 0.9$ & $6.8 \pm 0.6$ \\
\hline $\mathrm{BCNC}-5 \mathrm{~mL} / \mathrm{RC}$ yarn & $11.7 \pm 1.3$ & $9.5 \pm 0.7$ \\
\hline BCNC-5 mL/RC yarn with coating & $8.2 \pm 1.2$ & $8.8 \pm 0.8$ \\
\hline BCNC-10mL/RC yarn & $12.8 \pm 1.3$ & $11.2 \pm 0.9$ \\
\hline $\mathrm{BCNC}-10 \mathrm{~mL} / \mathrm{RC}$ yarn with coating & $8.9 \pm 1.4$ & $9.8 \pm 0.6$ \\
\hline
\end{tabular}

The knot-pull tensile strength of the yarns was also measured, because this is crucial for a surgical suture. The flexibility of the yarns decreased slightly after coating, as can be seen from the data in Table 2. The knot-pull tensile strength of all the coated yarns is lower than that of the uncoated materials. The reason for this may be the absence of drawing during the coating process. To improve their flexibility, the yarns were impregnated in PBS for $24 \mathrm{~h}$. The results show that after this treatment the BCNC-loaded yarns achieved satisfactory mechanical performance, with a knot-pull tensile strength of $9.8 \pm 0.6 \mathrm{~N}$. This meets the required strength mandated by the United States Pharmacopeia (USP) 37 (Chen et al., 2015).

In vitro enzymatic degradation. Enzymatic degradation studies were performed to determine the stability of the $\mathrm{RC}$ and $\mathrm{BCNC} / \mathrm{RC}$ fibers. It is known that chitin is biodegradable in vivo because the $\beta$ 1,4-glycosidic linkage in the polysaccharide chain can be hydrolyzed in the presence of lysozyme, which is ubiquitous in the body (Kang et al., 2017; Kobayashi et al., 2006; Porstmann et al., 1989) although its concentration varies in different locations (Porstmann et al., 1989). Thus, lysozyme was employed as a model enzyme for degradation studies, in accordance with previous reports (Kang et al., 2017; Eugene 
414 Khor, Wu, Lim, \& Guo, 2011; Liu et al., 2016). Fig. 4 depicts the degradation profiles after incubation in PBS and PBS/lysozyme solutions $(\mathrm{pH}=7.4)$ at $37^{\circ} \mathrm{C}$ for 15 days. A small $(<10 \%)$ weight loss was

416 observed for the RC and BCNC/RC fibers after immersion in PBS without lysozyme, probably due to

417 small pieces of fibers becoming detached from the bulk during shaking. This reveals the materials to 418 have high stability in PBS.

419 In contrast, significant degradation occurred in lysozyme-containing solutions. As the lysozyme 420 concentration increased from 0.2 to $1.0 \mathrm{mg} / \mathrm{mL}$, the degradation rate increased significantly: at 0.2 $421 \mathrm{mg} / \mathrm{mL} 71 \%$ of the mass remained after 15 days for the RC fibers, while at $1.0 \mathrm{mg} / \mathrm{mL}$ the residual mass was only $52 \%$. For the BCNC/RC fibers, the equivalent figures are $61 \%$ and $46 \%$. The presence of the BCNCs thus increases the degradation rate. It is thought that this arises due to the disintegration 424 accelerating properties of cellulose (Balaxi, Nikolakakis, Kachrimanis, \& Malamataris, 2009; Bitinis et 425 al., 2013; Yassin et al., 2015). However, the results are generally promising; the degradation rate was slow during the first 5 days of incubation, and then became more rapid in the later stages of the experiment, which is suitable for absorbable sutures. These degradation rates are on a par with the

428 literature. For instance, Kang et al. (Kang et al., 2017) found that as the lysozyme concentration increased

429 from 1 to $50 \mathrm{mg} / \mathrm{L}$, the degradation rate of a methacrylated carboxymethyl chitin hydrogel increased 430 from $50 \%$ weight loss in 60 h to $95 \%$ weight loss in 10 h. Zhao and co-workers (Zhao, Wu, Chen, \& 431 Xing, 2015) observed that another methacrylate-modified chitin material lost $80 \%$ of its mass in 12 days 432 in a $0.2 \mathrm{mg} / \mathrm{mL}$ lysozyme solution. 

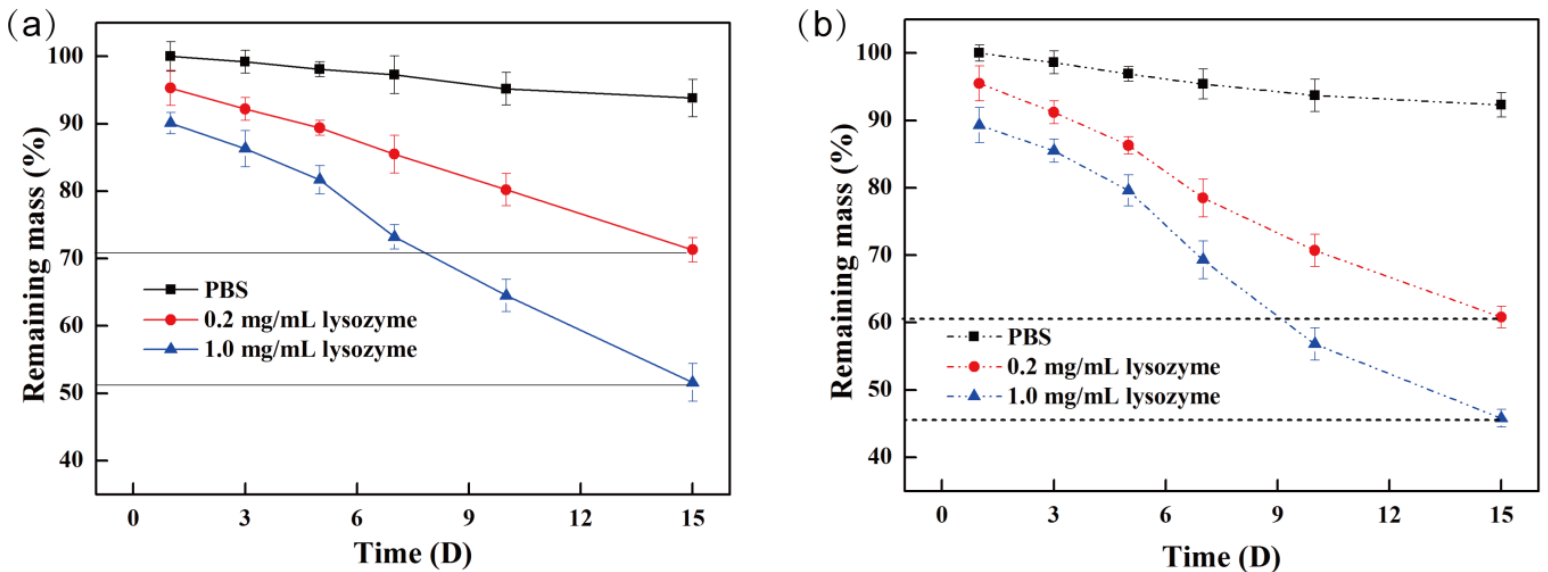

434 Fig. 4. Enzymatic degradation of (a) RC fibers and (b) BCNC-10 mL/RC fibers in different concentration lysozyme solutions. Data are shown as mean $\pm \mathrm{SD}, \mathrm{n}=3$.

\subsection{Evaluation of in vitro cytocompatibility}

It is known that chitin and cellulose themselves have very good biocompatibility, but it is still

necessary to determine whether the reprocessed composite products retain these properties. Two samples,

the BCNC-10 mL/RC filaments and the coated BCNC-10 mL/RC yarn were evaluated for their

cytotoxicity. It is evident (Fig. 5a) that after incubation for 1 and 3 days, the MTT absorbance of untreated

442 cells and those exposed to BCNC/RC filaments and coated BCNC/RC yarns are all similar. Compared

443 with the control, the MTT absorbance of cells exposed to the BCNC/RC filaments and coated yarn is a

444 little higher. This may be because the fibers can promote cell adhesion and proliferation, due to their high

445 specific surface area (Balen et al., 2016; Chen, Chang, Lee, \& Lai, 2014; Chung, Gamcsik, \& King, 
(a)

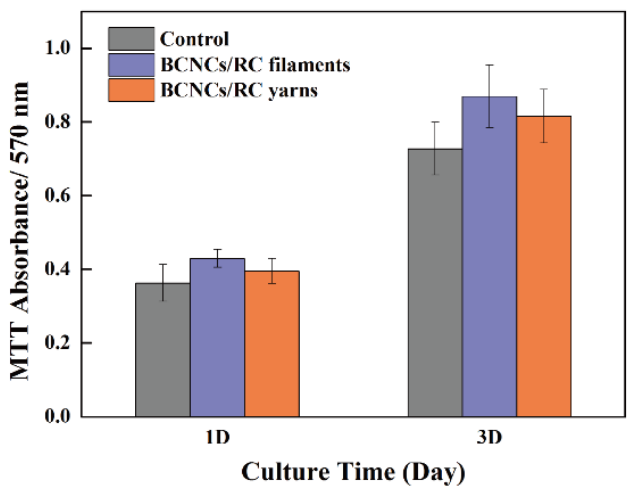

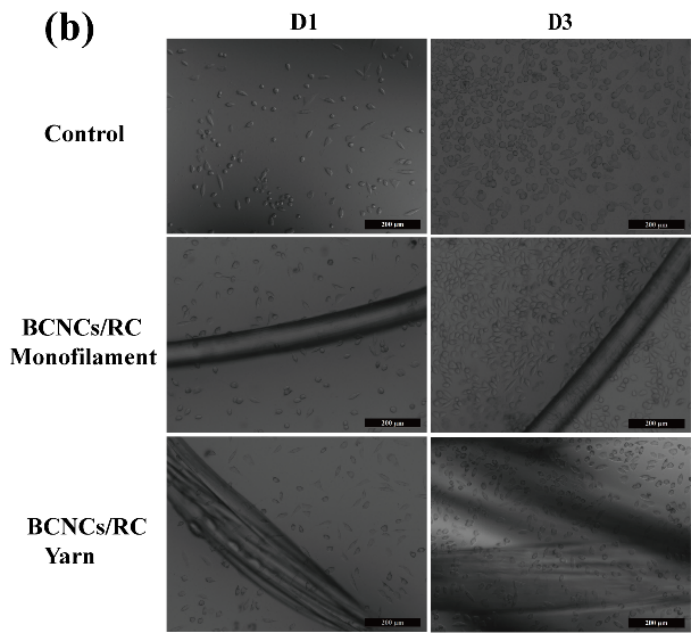

Fig. 5. (a) MTT results for L929 cells exposed to selected materials prepared in this work. Data are shown as mean $\pm \mathrm{SD}$, from three independent experiments with triplicates in each. (b) Microscopic images of L929 cells exposed to different materials. The scale bar in each panel represents $200 \mu \mathrm{m}$.

Images of the cells are shown in Fig. 5b. It is apparent that after 3 days culture there are more cells present than at the start of the experiment. The cell morphologies are the same for all conditions, but the cell densities with the $\mathrm{BCNC} / \mathrm{RC}$ fibers and yarn are higher than those without. Adhesion and proliferation on the fibers can be seen. The microscopic images thus confirm the MTT findings in Fig. 5 a.

\subsection{Evaluation of in vivo biocompatibility}

Images showing wound healing progression are presented in Fig. 6A. It is obvious that for the GroupI animals (negative control; no sutures) the wound did not heal in the 10 days after the operation. For Group-II (commercial sutures), Group-III (coated BCNC-10 mL/RC sutures) and Group-IV (uncoated BCNC-10 mL/RC sutures), slight swelling and inflammation was observed around the wounds after three days. However, after ten days, the suture lines fell off the skin without any external treatment, and the wound notches were completely healed with no signs of edema or rash. There were no significant differences between the $\mathrm{BCNC} / \mathrm{RC}$ sutures and PA suture in terms of the healing of the skin surface. 

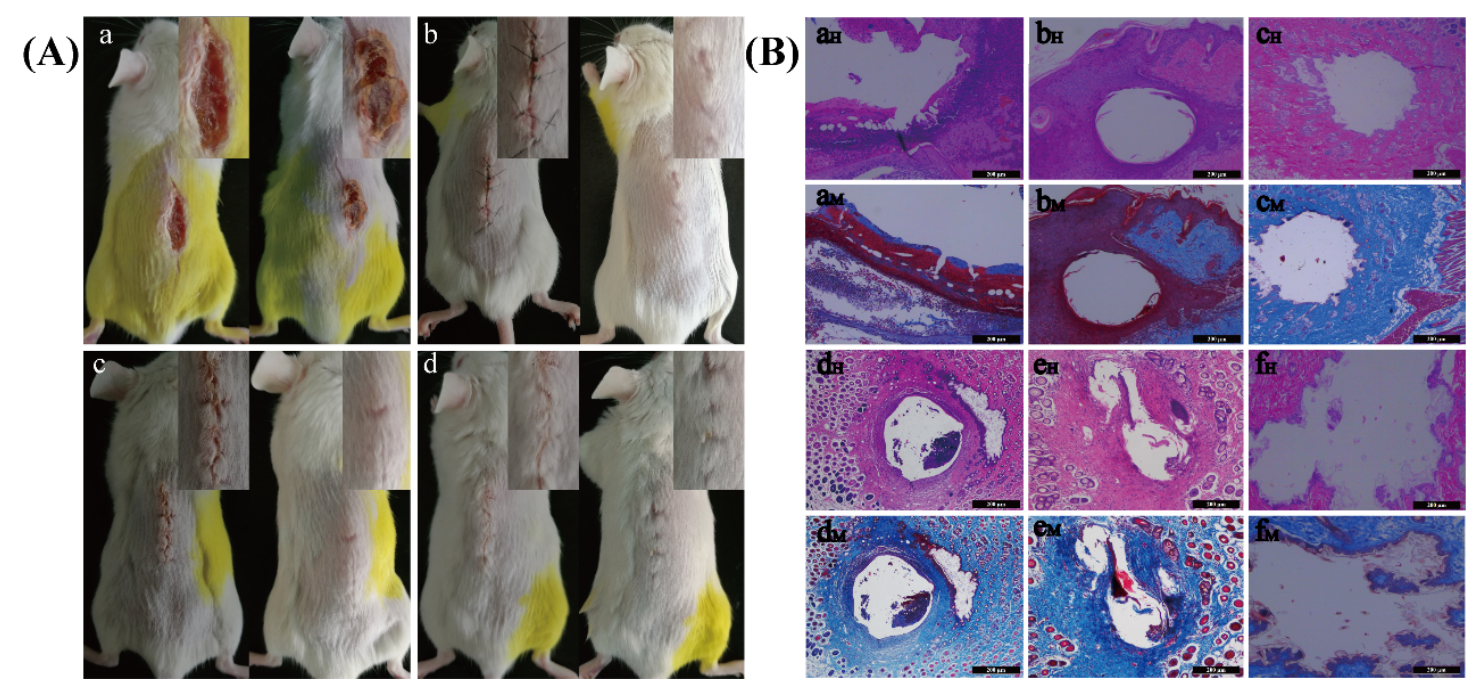

Fig. 6. (A) Images showing the wound healing process. Images are shown after 3 [left] and 10 days [right] for (a) mice without sutures (Group-I), (b) mice with polyamide sutures (Group-II), (c) mice sutured with coated BCNC-10 mL/RC yarns (Group-III) and (d) mice sutured with uncoated BCNC-10 mL/RC yarns (Group-IV). Insets depict enlargements of the wound area. (B) HE staining $\left(a_{H}-f_{H}\right)$ and Masson's trichrome staining $\left(a_{M}-f_{M}\right)$ for histological analysis. Images are shown for Group-I at 10 days $\left(a_{H}, a_{M}\right)$, Group-II at 3 days $\left(\mathrm{b}_{\mathrm{H}}, \mathrm{b}_{\mathrm{M}}\right)$, Group-II at 10 days $\left(\mathrm{c}_{\mathrm{H}}, \mathrm{c}_{\mathrm{M}}\right)$, Group-III at 3 days $\left(\mathrm{d}_{\mathrm{H}}, \mathrm{d}_{\mathrm{M}}\right)$, Group-III at 10 days $\left(\mathrm{e}_{\mathrm{H}}, \mathrm{e}_{\mathrm{M}}\right)$, and Group-IV at 10 days $\left(\mathrm{f}_{\mathrm{H}}, \mathrm{f}_{\mathrm{M}}\right)$. Bars represent $200 \mu \mathrm{m}$.

The horizontal cutting method was used for the analysis of wound histopathology. Representative images are given in Fig. 6B. Fig. 6B $\left(\mathrm{a}_{\mathrm{H}}, \mathrm{a}_{\mathrm{M}}\right)$ shows that for the unsutured Group-I mice the wounds were not completely healed after 10 days, consistent with Fig. 6A. Three and ten days after surgery, however, all the sections from Group-II, Group-III and Group-IV mice exhibited complete tissue morphology; no obvious decay or inflammatory lesions were found. With the longer recovery time, the amount of collagen around the suture increased, and the holes produced from the BCNC/RC sutures became deformed owing to the partial degradation of chitin. With the uncoated BCNC/RC sutures, the appearance of the hole was irregular (see Fig. $6 \mathrm{~B}\left(\mathrm{f}_{\mathrm{H}}, \mathrm{f}_{\mathrm{M}}\right)$ ), because the yarn began to unravel. No obvious adverse effects on the tissue were observed with the BCNC/RC sutures (cf. the Group-II control animals), and the $\mathrm{BCNC} / \mathrm{RC}$ composites could clearly promote wound healing. The efficacy of the BCNC/RC sutures was indistinguishable from that of the commercial PA suture after 10 days. 


\section{Conclusions}

In this work, nanocrystals were prepared successfully from bacterial cellulose (BC), with a width of ca. 20-50 nm and length of 100-300 nm. The BC nanocrystals (BCNCs) were then used for improving the mechanical performance of chitin fibers. Employing a wet spinning technology, the BCNCs and chitin solution were spun into BCNC/RC filaments, and further processed into yarns with the aid of a weaving technique. A detailed characterization comprising morphological observations, infrared spectroscopy, mechanical properties assessment, enzymatic degradability determination and in vitro biocompatibility evaluations indicated that the $\mathrm{BCNC} / \mathrm{RC}$ yarns meet the requirements for use as surgical sutures. It has been further proved with in vivo murine skin wound closure experiments that the $\mathrm{BCNC} / \mathrm{RC}$ material can promote wound healing without any adverse effects, and these novel systems perform on a par with commercial polyamide sutures. The results reported in this study thus provide a new method for the preparation of a strength-enhanced fiber, and the BCNC/RC blend yarn is expected to be a new candidate for application as medical sutures.

\section{Conflict of interest}

The authors declare no conflicts of interest.

\section{Acknowledgments}

This investigation was supported by grant 16410723700 from the Science and Technology Commission of Shanghai Municipality, the Biomedical Textile Materials "111 Project" of the Ministry of Education of China (No. B07024), the UK-China Joint Laboratory for Therapeutic Textiles (based at Donghua University), and the Yancheng Vocational Institute of Industry Technology.

\section{Appendix A. Supplementary information}

Further information is shown in the Supplementary Information. 


\section{References}

Amin, M. C., Abadi, A. G., \& Katas, H. (2014). Purification, characterization and comparative studies of spray-dried bacterial cellulose microparticles. Carbohydrate Polymers, 99(1), 180-189.

An, X., Long, Y., \& Ni, Y. (2016). Cellulose nanocrystal/hexadecyltrimethylammonium bromide/silver nanoparticle composite as a catalyst for reduction of 4-nitrophenol. Carbohydrate Polymers, $156,253-258$.

Anitha, A., Sowmya, S., Kumar, P. T. S., Deepthi, S., Chennazhi, K. P., Ehrlich, H., Tsurkan, M., \& Jayakumar, R. (2014). Chitin and chitosan in selected biomedical applications. Progress in Polymer Science, 39(9), 1644-1667.

Balaxi, M., Nikolakakis, I., Kachrimanis, K., \& Malamataris, S. (2009). Combined effects of wetting, drying, and microcrystalline cellulose type on the mechanical strength and disintegration of pellets. Journal of Pharmaceutical Sciences, 98(2), 676-689.

Balen, R., Costa, W. V. D., Andrade, J. D. L., Piai, J. F., Muniz, E. C., Companhoni, M. V., Nakamura, T. U., Lima, S. M., Andrade, L. H. D. C., \& Bittencourt, P. R. S. (2016). Structural, thermal, optical properties and cytotoxicity of PMMA/ZnO fibers and films: Potential application in tissue engineering. Applied Surface Science, 385, 257-267.

Barbosa, A., Robles, E., Ribeiro, J., Lund, R., Carreño, N., \& Labidi, J. (2016). Cellulose Nanocrystal Membranes as Excipients for Drug Delivery Systems. 9(12), 1002.

Bitinis, N., Fortunati, E., Verdejo, R., Bras, J., Kenny, J. M., Torre, L., \& Lópezmanchado, M. A. (2013). Poly(lactic acid)/natural rubber/cellulose nanocrystal bionanocomposites. Part II: properties evaluation. Carbohydrate Polymers, 96(2), 621-627. 
Cao, X., Dong, H., \& Li, C. M. (2007). New Nanocomposite Materials Reinforced with Flax Cellulose Nanocrystals in Waterborne Polyurethane. Biomacromolecules, 8(3), 899-904.

Chen, S. H., Chang, Y., Lee, K. R., \& Lai, J. Y. (2014). A three-dimensional dual-layer nano/microfibrous structure of electrospun chitosan/poly( d,l -lactide) membrane for the improvement of cytocompatibility. Journal of Membrane Science, 450(4904), 224-234.

Chen, X., Hou, D., Wang, L., Zhang, Q., Zou, J., \& Sun, G. (2015). Antibacterial Surgical Silk Sutures Using A High Performance Slow-release Carrier Coating System. ACS Applied Materials \& Interfaces, 7(40), 22394-22403.

Chen, Y., Chen, S., Wang, B., Yao, J., \& Wang, H. (2017). TEMPO-oxidized bacterial cellulose nanofibers-supported gold nanoparticles with superior catalytic properties. Carbohydrate Polymers, 160, 34-42.

Chung, S., Gamcsik, M. P., \& King, M. W. (2011). Novel scaffold design with multi-grooved PLA fibers. Biomedical Materials, 6(4), 045001.

Deepthi, S., Venkatesan, J., Kim, S. K., Bumgardener, J. D., \& Jayakumar, R. (2016). An overview of chitin or chitosan/nano ceramic composite scaffolds for bone tissue engineering. International Journal of Biological Macromolecules, 93, 1338-1353.

Dhivya, S., Saravanan, S., Sastry, T. P., \& Selvamurugan, N. (2015). Nanohydroxyapatite-reinforced chitosan composite hydrogel for bone tissue repair in vitro and in vivo. Journal of Nanobiotechnology, 13(1), 1-13.

Ding, F., Qian, X., Zhang, Q., Wu, H., Liu, Y., Xiao, L., Deng, H., Du, Y., \& Shi, X. (2015). Electrochemically induced reversible formation of carboxymethyl chitin hydrogel and tunable protein release. New Journal of Chemistry, 39(2), 1253-1259. 
Dobrovol'skaya, I. P., Kasatkin, I. A., Yudin, V. E., Ivan'kova, E. M., \& Elokhovskii, V. Y. (2015). Supramolecular structure of chitin nanofibrils. Polymer Science Series A, 57(1), 52-57.

Esmaeili, C., Abdi, M. M., Mathew, A. P., Jonoobi, M., Oksman, K., \& Rezayi, M. (2015). Synergy Effect of Nanocrystalline Cellulose for the Biosensing Detection of Glucose. Sensors, 15(10), 24681-24697.

Espinha, A., Guidetti, G., Serrano, M. C., Frkapetesic, B., Dumanli, A. G., Hamad, W. Y., Blanco, A., Lopez, C., \& Vignolini, S. (2016). Shape Memory Cellulose-based Photonic Reflectors. ACS Applied Materials \& Interfaces, 8 (46), 31935-31940.

Gençer, A., Schütz, C., \& Thielemans, W. (2016). Influence of the Particle Concentration and Marangoni Flow on the Formation of Cellulose Nanocrystal Films. Langmuir, 33(1), 228-234.

Gorgieva, S., Girandon, L., \& Kokol, V. (2017). Mineralization potential of cellulose-nanofibrils reinforced gelatine scaffolds for promoted calcium deposition by mesenchymal stem cells. Materials Science \& Engineering C, 73, 478-489.

Habibi, Y., Lucia, L. A., \& Rojas, O. J. (2010). Cellulose nanocrystals: chemistry, self-assembly, and applications. Chemical Reviews, 110(6), 3479-3500.

Huang, Y., Zhong, Z., Duan, B., Zhang, L., Yang, Z., Wang, Y., \& Ye, Q. (2014). Novel fibers fabricated directly from chitin solution and their application as wound dressing. Journal of Materials Chemistry B, 2(2), 3427-3432.

Jayakumar, R., Chennazhi, K. P., Srinivasan, S., Nair, S. V., Furuike, T., \& Tamura, H. (2011). Chitin Scaffolds in Tissue Engineering. International Journal of Molecular Sciences, 12(3), 1876-1887.

Kai, M., Müller, A., Beyer, R., Hermanutz, F., \& Buchmeiser, M. R. (2015). Multifilament cellulose/chitin blend yarn spun from ionic liquids. Carbohydrate Polymers, 131, 34-40. 
Kang, W., Bi, B., Zhuo, R., \& Jiang, X. (2017). Photocrosslinked methacrylated carboxymethyl chitin hydrogels with tunable degradation and mechanical behavior. Carbohydrate Polymers, 160, 1825.

Ketabchi, M. R., Khalid, M., Ratnam, C. T., \& Walvekar, R. (2016). Mechanical and thermal properties of polylactic acid composites reinforced with cellulose nanoparticles extracted from kenaf fibre. 3(12), 125301.

Khor, E., \& Lim, L. Y. (2003). Implantable applications of chitin and chitosan. Biomaterials, 24(13), 2339-2349.

Khor, E., Wu, H., Lim, L. Y., \& Guo, C. M. (2011). Chitin-Methacrylate: Preparation, Characterization and Hydrogel Formation. Materials, 4(10), 360-391.

Kim, H. J., Park, S., Kim, S. H., Ji, H. K., Yu, H., Kim, H. J., Yang, Y. H., Kan, E., Yong, H. K., \& Sang, H. L. (2015). Biocompatible cellulose nanocrystals as supports to immobilize lipase. Journal of Molecular Catalysis B Enzymatic, 122, 170-178.

Kobayashi, S., Makino, A., Matsumoto, H., Kunii, S., Ohmae, M., Kiyosada, T., Makiguchi, K., Matsumoto, A., Horie, M., \& Shoda, S. (2006). Enzymatic polymerization to novel polysaccharides having a glucose- $\mathrm{N}$-acetylglucosamine repeating unit, a cellulose-chitin hybrid polysaccharide. Biomacromolecules, 7(7), 1644-1656.

Lee, W. J., Clancy, A. J., Kontturi, E., Bismarck, A., \& Shaffer, M. S. P. (2016). Strong and Stiff: High Performance Cellulose Nanocrystal/Polyvinyl Alcohol Composite Fibers. ACS Applied Materials \& Interfaces, 8(46), 31500-31504.

Leung, A. C. W., Lam, E., Chong, J., Hrapovic, S., \& Luong, J. H. T. (2013). Reinforced plastics and aerogels by nanocrystalline cellulose. Journal of Nanoparticle Research, 15(5), 1-24. 
Li, Y., Jiang, H., Zheng, W., Gong, N., Chen, L., Jiang, X., \& Yang, G. (2015). Bacterial cellulosehyaluronan nanocomposite biomaterials as wound dressings for severe skin injury repair. Journal of Materials Chemistry B, 3(17), 3498-3507.

Liu, H., Liu, J., Qi, C., Fang, Y., Zhang, L., Zhuo, R., \& Jiang, X. (2016). Thermosensitive injectable insitu forming carboxymethyl chitin hydrogel for three-dimensional cell culture. Acta Biomaterialia, 35, 228-237.

Liu, X., Ma, L., Mao, Z., \& Gao, C. (2011). Chitosan-Based Biomaterials for Tissue Repair and Regeneration. Advances in Polymer Science, 244(2), 81-128.

Maslova, M. V., Uspenskii, S. A., Gal'Braikh, L. S., \& Kil'Deeva, N. R. (2016). Surgical Sutures Modified with Polysaccharide Composites. Fibre Chemistry, 48(3), 253-257.

Musa, A., Ahmad, M. B., Hussein, M. Z., Saiman, M. I., \& Sani, H. A. (2017). Preparation, characterization and catalytic activity of biomaterial-supported copper nanoparticles. Research on Chemical Intermediates, 43(2), 801-815.

Nguyen, V. Q., Ishihara, M., Kinoda, J., Hattori, H., Nakamura, S., Ono, T., Miyahira, Y., \& Matsui, T. (2014). Development of antimicrobial biomaterials produced from chitin-nanofiber sheet/silver nanoparticle composites. Journal of Nanobiotechnology, 12(1), 49.

Oliveira, R. L. D., Barud, H. D. S., Assunção, R. M. N. D., Meireles, C. D. S., Carvalho, G. O., Filho, G. R., Messaddeq, Y., \& Ribeiro, S. J. L. (2011). Synthesis and characterization of microcrystalline cellulose produced from bacterial cellulose. Journal of Thermal Analysis and Calorimetry, 106(3), 703-709.

Pirich, C. L., Freitas, R. A. D., Woehl, M. A., Picheth, G. F., Petri, D. F. S., \& Sierakowski, M. R. (2015). Bacterial cellulose nanocrystals: impact of the sulfate content on the interaction with xyloglucan. 
621

Pogorielov, M., Kravtsova, A., Reilly, G. C., Deineka, V., Tetteh, G., Kalinkevich, O., Pogorielova, O., Moskalenko, R., \& Tkach, G. (2017). Experimental evaluation of new chitin-chitosan graft for duraplasty. Journal of Materials Science Materials in Medicine, 28(2), 34.

Porstmann, B., Jung, K., Schmechta, H., Evers, U., Pergande, M., Porstmann, T., Kramm, H. J., \& Krause, H. (1989). Measurement of lysozyme in human body fluids: Comparison of various enzyme immunoassay techniques and their diagnostic application. Clinical Biochemistry, 22(5), 349355.

Qing, W., Wang, Y., Wang, Y., Zhao, D., Liu, X., \& Zhu, J. (2016). The modified nanocrystalline cellulose for hydrophobic drug delivery. Applied Surface Science, 366, 404-409.

Riccardoaa, M. (2009). Chitins and chitosans for the repair of wounded skin, nerve, cartilage and bone. Carbohydrate Polymers, 76(2), 167-182.

Sacui, I. A., Nieuwendaal, R. C., Burnett, D. J., Stranick, S. J., Jorfi, M., Weder, C., Foster, E. J., Olsson, R. T., \& Gilman, J. W. (2014). Comparison of the Properties of Cellulose Nanocrystals and Cellulose Nanofibrils Isolated from Bacteria, Tunicate, and Wood Processed Using Acid, Enzymatic, Mechanical, and Oxidative Methods. ACS applied materials \& interfaces, 6(9), $6127-6138$.

Saralegi, A., Rueda, L., Martin, L., Arbelaiz, A., Eceiza, A., \& Corcuera, M. A. (2013). From elastomeric to rigid polyurethane/cellulose nanocrystal bionanocomposites. Composites Science \& Technology, 88(10), 39-47.

Schyrr, B., Pasche, S., Voirin, G., Weder, C., Simon, Y. C., \& Foster, E. J. (2014). Biosensors based on porous cellulose nanocrystal-poly(vinyl alcohol) scaffolds. ACS applied materials \& interfaces, 
6(15), 12674-12683.

Shao, K., Han, B., Gao, J., Jiang, Z., Liu, W., Liu, W., \& Liang, Y. (2015). Fabrication and feasibility study of an absorbable diacetyl chitin surgical suture for wound healing. Journal of Biomedical Materials Research Part B Applied Biomaterials, 104(1), 116-125.

Singh, N., Chen, J., Koziol, K. K., Hallam, K. R., Janas, D., Patil, A. J., Hanley, G. J., \& Rahatekar, S. S. (2016). Chitin and carbon nanotube composites as biocompatible scaffolds for neuron growth. Nanoscale, 8(15), 8288-8299.

Singh, N., Koziol, K. K. K., Chen, J., Patil, A. J., Gilman, J. W., Trulove, P. C., Kafienah, W., \& Rahatekar, S. S. (2013). Ionic liquids-based processing of electrically conducting chitin nanocomposite scaffolds for stem cell growth. Green Chemistry, 15(5), 1192-1202.

Skołucka-Szary, K., Ramięga, A., Piaskowska, W., Janicki, B., Grala, M., Rieske, P., Stoczyńska-Fidelus, E., \& Piaskowski, S. (2015). Chitin dipentanoate as the new technologically usable biomaterial. Materials Science and Engineering: C, 55, 50-60.

Sunasee, R., Hemraz, U. D., \& Ckless, K. (2016). Cellulose nanocrystals: a versatile nanoplatform for emerging biomedical applications. Expert Opinion on Drug Delivery, 13(9), 1243-1256.

Teimouri, A., \& Azadi, M. (2016). $\beta$-Chitin/gelatin/nanohydroxyapatite composite scaffold prepared through freeze-drying method for tissue engineering applications. Polymer Bulletin, 73(12), 117.

Teimouri, A., Ebrahimi, R., Emadi, R., Beni, B. H., \& Chermahini, A. N. (2015). Nano-composite of silk fibroin-chitosan/Nano $\mathrm{ZrO}_{2}$ for tissue engineering applications: Fabrication and morphology. International Journal of Biological Macromolecules, 76, 292-302.

Vasconcelos, N. F., Feitosa, J. P. A., da Gama, F. M. P., Morais, J. P. S., Andrade, F. K., de Souza, M. d. 
S. M., \& de Freitas Rosa, M. (2017). Bacterial cellulose nanocrystals produced under different hydrolysis conditions: Properties and morphological features. Carbohydrate Polymers, 155, 425-431.

Viju, S., \& Thilagavathi, G. (2013). Effect of chitosan coating on the characteristics of silk-braided sutures. Journal of Industrial Textiles, 42(3), 256-268.

Wang, B., Torresrendon, J. G., Yu, J., Zhang, Y., \& Walther, A. (2015). Aligned Bioinspired Cellulose Nanocrystal-Based Nanocomposites with Synergetic Mechanical Properties and Improved Hygromechanical Performance. ACS applied materials \& interfaces, 7(8), 4595-4607.

Wang, X., Kong, D., Zhang, Y., Wang, B., Li, X., Qiu, T., Song, Y., \& Zhi, L. (2016). All-biomaterial supercapacitor derived from bacterial cellulose. Nanoscale, 8(17), 9146-9150.

Wu, H. L., Bremner, D. H., Li, H. Y., Shi, Q. Q., Wu, J. Z., Xiao, R. Q., \& Zhu, L. M. (2016). A novel multifunctional biomedical material based on polyacrylonitrile: Preparation and characterization. Materials Science \& Engineering C, 62, 702-709.

Xie, H., Khajanchee, Y. S., Teach, J. S., \& Shaffer, B. S. (2008). Use of a chitosan-based hemostatic dressing in laparoscopic partial nephrectomy. Journal of Biomedical Materials Research Part B Applied Biomaterials, 85(1), 267-271.

Yan, W., Shen, L., Ji, Y., Yang, Q., \& Shen, X. (2014). Chitin nanocrystal reinforced wet - spun chitosan fibers. Journal of Applied Polymer Science, 131(19), 5829-5836.

Yang, X., \& Cranston, E. D. (2014). Chemically Cross-Linked Cellulose Nanocrystal Aerogels with Shape Recovery and Superabsorbent Properties. Chemistry of Materials, 26(20), 6016-6025.

Yassin, S., Goodwin, D. J., Anderson, A., Sibik, J., Wilson, D. I., Gladden, L. F., \& Zeitler, J. A. (2015). The Disintegration Process in Microcrystalline Cellulose Based Tablets, Part 1: Influence of 

3440-3450.

688 Yoon, O. J. (2016). Thermal characteristics of polyethylene oxide and functionalized bacterial cellulose whisker nanoparticle composite nanofibers. Macromolecular Research, 11(12), 1-7.

690

691

692

693

694

695

696 